\title{
Mechanical analysis of deepwater drilling riser system based on multibody system dynamics
}

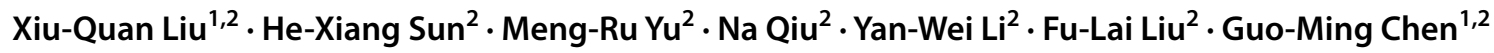

Received: 21 March 2020 / Published online: 9 October 2020

(c) The Author(s) 2020

\begin{abstract}
A multibody system including a drilling riser system, tensioners and a floating platform is key equipment for offshore oil and gas drilling. Most of the previous studies only focus on the drilling riser system rather than the multibody system. Mechanical characteristics of the deepwater drilling riser system cannot be analyzed accurately in a simplified model. Therefore, a three-dimensional multibody analysis program is developed. The static and dynamic characteristics of the deepwater drilling riser system under different platform motions are analyzed based on the developed program. The results show that the static displacement of the riser system with tensioners is smaller than that without tensioners, which means the tensioners can suppress the deformation of the riser system. Under surge and sway motions of the platform, the dynamic displacement of the riser system with tensioners is also smaller than that without tensioners due to the tensioner suppression effect. Besides, the heave motion induces a uniform axial vibration of the riser system, while roll and pitch motions excite the riser system to vibrate laterally. Compared with the stress amplitude due to surge and sway motions, the stress amplitude of the riser system due to heave, roll and pitch motions is relatively small but cannot be neglected.
\end{abstract}

Keywords Deepwater $\cdot$ Riser $\cdot$ Tensioner $\cdot$ Drilling platform $\cdot$ Multibody dynamics

\section{List of symbols}

A Cross-sectional area of riser, $\mathrm{m}^{2}$

$A_{\mathrm{p}} \quad$ Sectional area of piston, $\mathrm{m}^{2}$

$A_{\mathrm{r}} \quad$ Sectional area of piston rod, $\mathrm{m}^{2}$

$A_{0} \quad$ Amplitude of regular wave, $\mathrm{m}$

$c_{\mathrm{L}} \quad$ Lateral damping coefficient, $\mathrm{N} /(\mathrm{m} / \mathrm{s})$

$c_{\mathrm{a}} \quad$ Axial damping coefficient, $\mathrm{N} /(\mathrm{m} / \mathrm{s})$

$C_{\mathrm{M}} \quad$ Inertia coefficient (dimensionless)

$C_{\mathrm{D}} \quad$ Drag coefficient (dimensionless)

$D_{\mathrm{h}} \quad$ Hydrodynamic diameter of the riser system, $\mathrm{m}$

E Elastic modulus of riser material, $\mathrm{Pa}$

$F_{\mathrm{L}} \quad$ Lateral marine environmental load on the riser system, $\mathrm{N}$

$F_{\text {a }} \quad$ Axial hydrodynamic load, $\mathrm{N}$

$T$ Axial tension of the riser system, $\mathrm{N}$

Edited by Xiu-Qiu Peng

Xiu-Quan Liu

1xqmcae@163.com

1 National Engineering Laboratory of Offshore Geophysical and Exploration Equipment, China University of Petroleum, Qingdao 266580, China

2 Centre for Offshore Engineering and Safety Technology, China University of Petroleum, Qingdao 266580, China
$W \quad$ Weight of per unit length of the riser system in seawater, $\mathrm{N}$

I Area moment of inertia of riser cross-section, $\mathrm{m}^{4}$

$J \quad$ Moment of inertia of riser unit, $\mathrm{kg} \mathrm{m}^{2}$

$P_{\mathrm{h} 0} \quad$ Initial pressure of high-pressure gas, $\mathrm{Pa}$

$P_{\mathrm{L} 0} \quad$ Initial pressure of low-pressure gas, $\mathrm{Pa}$

$P_{\mathrm{h}} \quad$ High-pressure gas pressure, $\mathrm{Pa}$

$P_{\mathrm{L}} \quad$ Low-pressure gas pressure, $\mathrm{Pa}$

$V_{\mathrm{h} 0} \quad$ Initial volume of high-pressure gas, $\mathrm{m}^{3}$

$V_{\mathrm{L} 0}$ Initial volume of low-pressure gas, $\mathrm{m}^{3}$

$V_{\mathrm{h}} \quad$ Current volume in the high-pressure gas vessels, $\mathrm{m}^{3}$

$V_{\mathrm{L}} \quad$ Current volume in the low-pressure gas vessels, $\mathrm{m}^{3}$

$M \quad$ Mass of piston rod, $\mathrm{kg}$

$S_{0} \quad$ Mean offset of platform, m

$R \quad$ Response amplitude (dimensionless)

$Z_{\mathrm{t}} \quad$ Piston stroke, $\mathrm{m}$

$l \quad$ Unit length of riser, $\mathrm{m}$

$m \quad$ Mass of the riser per unit length, $\mathrm{kg}$

$u \quad$ Axial displacement of riser system, $\mathrm{m}$

$z \quad$ The depth of water, $m$

$v_{\mathrm{w}} \quad$ Water particle velocity induced by wave, $\mathrm{m} / \mathrm{s}$

$\dot{v}_{\mathrm{w}} \quad$ Water particle acceleration induced by wave, $\mathrm{m} / \mathrm{s}^{2}$

$v_{\mathrm{c}} \quad$ Steady current velocity, $\mathrm{m} / \mathrm{s}$

$w$ Wave frequency, $\mathrm{rad} / \mathrm{s}$

$x \quad$ Lateral displacement of riser system, $\mathrm{m}$ 
$\dot{x} \quad$ Riser velocity, $\mathrm{m} / \mathrm{s}$

$\ddot{x} \quad$ Riser acceleration, $\mathrm{m} / \mathrm{s}^{2}$

$k_{\mathrm{T}} \quad$ Translation spring coefficient, $\mathrm{N} / \mathrm{m}$

$b_{\mathrm{T}} \quad$ Translation damping coefficient, $\mathrm{N} /(\mathrm{m} / \mathrm{s})$

$k_{\mathrm{R}} \quad$ Rotational spring coefficient, $\mathrm{N} \mathrm{m} / \mathrm{rad}$

$b_{\mathrm{R}}$ Rotational damping coefficient, $\mathrm{N} \mathrm{m} /(\mathrm{rad} / \mathrm{s})$

\section{Greek letters}

$\rho \quad$ Sea water density, $\mathrm{kg} / \mathrm{m}^{3}$

$\gamma \quad$ Adiabatic gas constant (dimensionless)

$\zeta \quad$ Damping ratio (dimensionless)

$\varphi \quad$ The phase difference between platform motion and wave, rad

\section{Introduction}

A drilling riser system is a key component connecting the drilling platform with subsea wellhead in offshore drilling engineering. The top end of the riser system is hung on the drilling platform via tensioners, and the bottom end of the riser system is connected to the subsea wellhead via lower marine riser package (LMRP) and blowout preventer (BOP) (Chen et al. 2013). The drilling riser system, platform and tensioners form a multibody system. The drilling riser system suffers marine environment loads and interaction loads between the multibody system such as tension force and platform motions. The combined loads cause the drilling riser system deformation and vibration. An excessive deformation and vibration may lead to failure of the riser system. It is necessary to conduct multibody mechanical analysis to reveal the mechanical characteristics of the deepwater drilling riser system accurately, which is of great significance to the safety of the drilling riser system.

Mechanical characteristics of the multibody system are difficult to be analyzed due to its complex structure. Therefore, the drilling riser system is often taken as an individual research object. Tensioners are simplified as a constant tension force, and the drilling platform is taken as a displacement boundary applied on the top of the riser system. Then, a simplified mechanical model for the riser analysis can be derived. A series of static and dynamic analysis was conducted to study the mechanical behavior of the riser system based on the simplified model (Patel and Seyed 1995; Chen et al. 2013; Zhou and Xu 2018; Zhang et al. 2019). Actually, the tension force applied on the top of the riser system varies with the heave motion of the drilling platform. A coupling model including the riser system and tensioners is then introduced to simulate the axial dynamic behavior of the riser system. Sullivan et al. (2004) used spring elements to simulate tensioners to conduct suspension dynamic analysis of a riser system. Lang et al. (2009) developed a dynamic analysis unit of tensioners and coupled it with the dynamic analysis model of a riser system to conduct riser recoil analysis. Wang et al. (2013) proposed a nonlinear tensioner model considering the nonlinear stiffness and friction. The tensioner is simplified as a linear model, and the predicted axial responses are compared with that of the nonlinear model. Zhang et al. (2013) established a tension force and stiffness calculation model of tensioners to analyze the recoil response of a riser system. Wang and Liu (2018) developed a mathematical model of a direct-acting tensioner system to analyze the effect of internal friction of tensioner cylinder on the tensioner performance and axial dynamics of a riser system.

In the aforementioned investigations, the multibody system is simplified into a drilling riser system or a riser/tensioner coupling system in which tensioners are often simulated by spring elements for axial dynamic analysis of a riser system. A more accurate analysis method needs to be proposed to analyze the complex multibody system. Multibody dynamics may be a good choice since it can handle linearly and nonlinearly elastic multibody systems with arbitrary topologies (Amirouche 2006; Bauchau 2011). In recent years, multibody dynamics has been applied gradually to ocean engineering (Lee and Roh 2018). Cha et al. (2010) conducted a dynamic response simulation of a heavy cargo suspended by a floating crane based on multibody dynamics. Wang and Sweetman (2013) carried out a multibody analysis of an offshore floating wind generator platform and its units based on multibody dynamics. $\mathrm{Ku}$ and Ha (2014) introduced multibody dynamics to study the dynamic characteristics of different suspension cables and the motion of a crane. Ham et al. (2015) conducted multibody dynamic research on a floating crane on water and revealed dynamic characteristics of the multibody system. Lee et al. (2015) and Yang et al. (2017) introduced multibody dynamics theory into the recoil analysis of a riser system. Besides the riser recoil analysis based on multibody dynamics, an extensional multibody analysis model including a drilling riser system, tensioners and a floating platform needs to be established to study the static and dynamic mechanical behavior of the drilling riser system.

Problems that involve mechanical analysis of a deepwater drilling riser system based on multibody system dynamics are addressed in this study. The remainder of this paper is organized as follows. Section 2 describes the basic theoretical models of the multibody system. Section 3 presents the multibody simulation models. Section 4 shows the static and dynamic characteristics of the drilling riser system based on multibody dynamics. Section 5 provides conclusions.

\section{Theoretical models}

Figure 1 shows a multibody system including a floating platform, a drilling riser system and tensioners. The drilling riser system including upper flex joint (UFJ), telescopic 
joints, riser joints, lower flex joint (LFJ), LMRP and BOP is key equipment connecting the drilling platform and the subsea wellhead. The top end of the riser system is hung on the drilling platform via tensioners and upper flex joint, and the bottom end of the riser system is connected to BOP, subsea wellhead and conductor via LMRP. Tensioners provide the riser system with a tension force in the axial direction opposite to gravity. The upper part of the tensioners is directly connected to the drilling platform, and the lower part of the tensioners links to tension rings on the outside of the telescopic joint. The multibody system deforms and vibrates under marine environment loads. In addition, each body of the multibody system also interacts with each other complicatedly. Therefore, the mechanical analysis model for each body should be established, respectively, and then assembled into a multibody analysis model. Theoretical models of each body will be presented in the following subsections.

\subsection{Riser model}

The riser system vibrates laterally under environment loads and horizontal platform motion, as shown in Fig. 1. Besides, the riser system may also vibrate axially under the excitation of platform heave motion. The lateral and axial dynamic equations of the riser system can be given, respectively (Park and Jung 2002; Liu et al. 2016a, b).

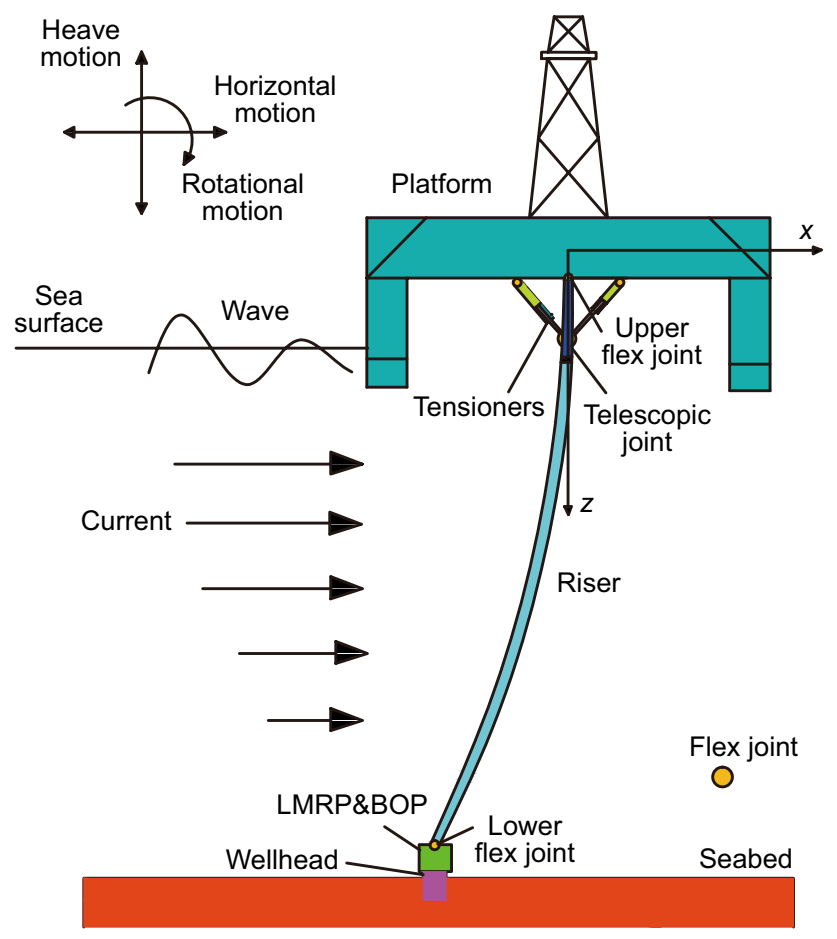

Fig. 1 Multibody system

$$
\begin{aligned}
m \frac{\partial^{2} x(z, t)}{\partial t^{2}} & +c_{\mathrm{L}} \frac{\partial x(z, t)}{\partial t}+\frac{\partial^{2}}{\partial z^{2}}\left(E I(z) \frac{\partial^{2} x(z, t)}{\partial z^{2}}\right) \\
& -\frac{\partial}{\partial z}\left(T(z) \frac{\partial x(z, t)}{\partial z}\right)=F_{\mathrm{L}}(z, t) \\
m \frac{\partial^{2} u(z, t)}{\partial t^{2}} & +c_{\mathrm{a}} \frac{\partial u(z, t)}{\partial t}-\frac{\partial}{\partial z}\left(E A(z) \frac{\partial u(z, t)}{\partial z}\right)=W-F_{\mathrm{a}}(z, t)
\end{aligned}
$$

where $x$ is the lateral displacement of the riser system, $u$ is the axial displacement of the riser system, $z$ is the depth, $E$ is the elastic modulus of riser material, $I$ is the area moment of inertia of riser cross-section, $T$ is axial tension of the riser system, $A$ is the cross-sectional area of the riser, $c_{\mathrm{L}}$ is the lateral damping coefficient, $c_{\mathrm{a}}$ is the axial damping coefficient, $m$ is the mass of the riser per unit length, $W$ is the weight per unit length of the riser system in seawater, $F_{\mathrm{L}}$ is the lateral marine environmental load on the riser system, $F_{\mathrm{a}}$ is the axial hydrodynamic load which is little and can be neglected since the riser system is connected with the subsea wellhead.

The lateral marine environment load per unit length on the riser system above the mudline are written as follows (Liu et al. 2016a, b):

$$
\begin{aligned}
F_{\mathrm{L}}(z, t)= & \frac{\pi}{4} \rho C_{\mathrm{M}} D_{\mathrm{h}}^{2} \dot{v}_{\mathrm{W}}-\frac{\pi}{4} \rho\left(C_{\mathrm{M}}-1\right) D_{\mathrm{h}}^{2} \ddot{x} \\
& +\frac{1}{2} \rho D_{\mathrm{h}} C_{\mathrm{D}}\left(v_{\mathrm{W}}+v_{\mathrm{c}}-\dot{x}\right)\left|v_{\mathrm{W}}+v_{\mathrm{c}}-\dot{x}\right|
\end{aligned}
$$

where $\rho$ is the sea water density, $D_{\mathrm{h}}$ is the hydrodynamic diameter of the riser system, $C_{\mathrm{M}}$ is the inertia coefficient, $C_{\mathrm{D}}$ is the drag coefficient, $v_{\mathrm{w}}$ is the water particle velocity induced by a wave, $\dot{v}_{\mathrm{w}}$ is the water particle acceleration induced by a wave, $v_{\mathrm{c}}$ is the steady current velocity, $\dot{x}$ is the riser velocity and $\ddot{x}$ is the riser acceleration.

\subsection{Tensioner model}

Tensioners are equipped between a drilling platform and the riser system to compensate the heave motion of the platform and prevent buckling of the riser system due to its own weight (Haziri 2011). Tensioners are mainly divided into two types: the wireline riser tensioner (WRT) and the direct-acting tensioner (DAT). The DAT is becoming predominant in recent deepwater field development due to its simple structure and high payload (Wang and Liu 2018). Therefore, the DAT system is selected for the multibody analysis, as shown in Fig. 2.

Figure 2 shows that the DAT typically consists of hydro-pneumatic tensioner cylinders, oil-gas accumulators, high-pressure gas vessels and low-pressure gas vessels. The pressure difference between high-pressure gas vessels and low-pressure gas vessels ensures that a tension 


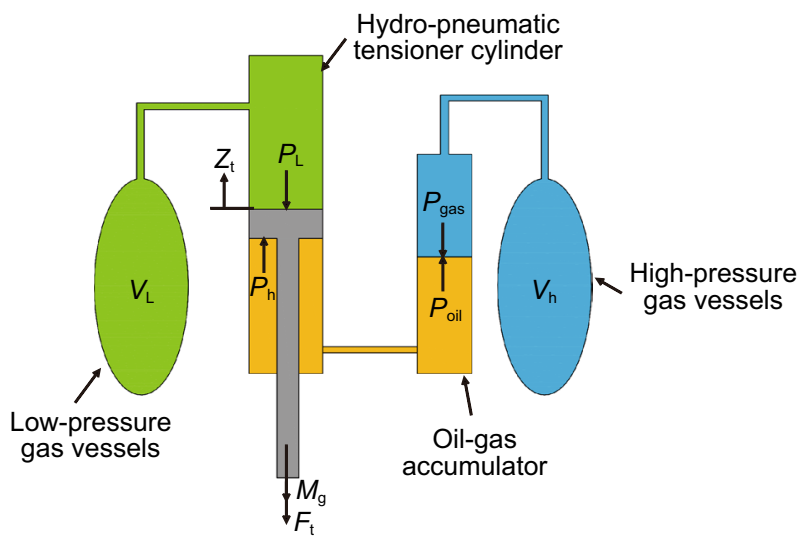

Fig. 2 The DAT system

force is applied to the riser system. The tension force of a single DAT can be calculated as follows (Wang and Liu 2018; Chen et al. 2019).

$F_{\mathrm{t}}=P_{\mathrm{h}}\left(A_{\mathrm{p}}-A_{\mathrm{r}}\right)-P_{\mathrm{L}} A_{\mathrm{p}}-M g$

where $P_{\mathrm{h}}$ and $P_{\mathrm{L}}$ are high pressure and low pressure on two sides of the piston, respectively, $A_{\mathrm{p}}$ is the sectional area of the piston, $A_{\mathrm{r}}$ is the sectional area of the piston rod and $M$ is the mass of the piston rod.

The high pressure $P_{\mathrm{h}}$ and low pressure $P_{\mathrm{L}}$ can be written as follows:

$P_{\mathrm{h}}=P_{\mathrm{h} 0}\left(\frac{V_{\mathrm{h} 0}}{V_{\mathrm{h}}}\right)^{\gamma}$

$P_{\mathrm{L}}=P_{\mathrm{L} 0}\left(\frac{V_{\mathrm{L} 0}}{V_{\mathrm{L}}}\right)^{\gamma}$

where $\gamma$ is the adiabatic gas constant, $P_{\mathrm{h} 0}$ and $V_{\mathrm{h} 0}$ are initial pressure and volume in the high-pressure gas vessels, respectively; $P_{\mathrm{L} 0}$ and $V_{\mathrm{L} 0}$ are initial pressure and volume in the low-pressure gas vessels, respectively; $V_{\mathrm{h}}$ is the current volume in the high-pressure gas vessels and $V_{\mathrm{L}}$ is the current volume in the low-pressure gas vessels.

The gas volume in the high- and low-pressure gas vessels changes with poison stroke. Assuming the hydraulic fluid is incompressible, the gas volume in the gas vessels can be written as follows:

$V_{\mathrm{h}}=V_{\mathrm{h} 0}+\left(A_{\mathrm{p}}-A_{\mathrm{r}}\right) Z_{\mathrm{t}}$

$V_{\mathrm{L}}=V_{\mathrm{L} 0}-A_{\mathrm{p}} Z_{\mathrm{t}}$

where $Z_{\mathrm{t}}$ is the piston stroke.

Substituting Eqs. (7) and (8) into Eqs. (5) and (6), respectively, the high pressure $P_{\mathrm{h}}$ and low pressure $P_{\mathrm{L}}$ can be expressed as follows:

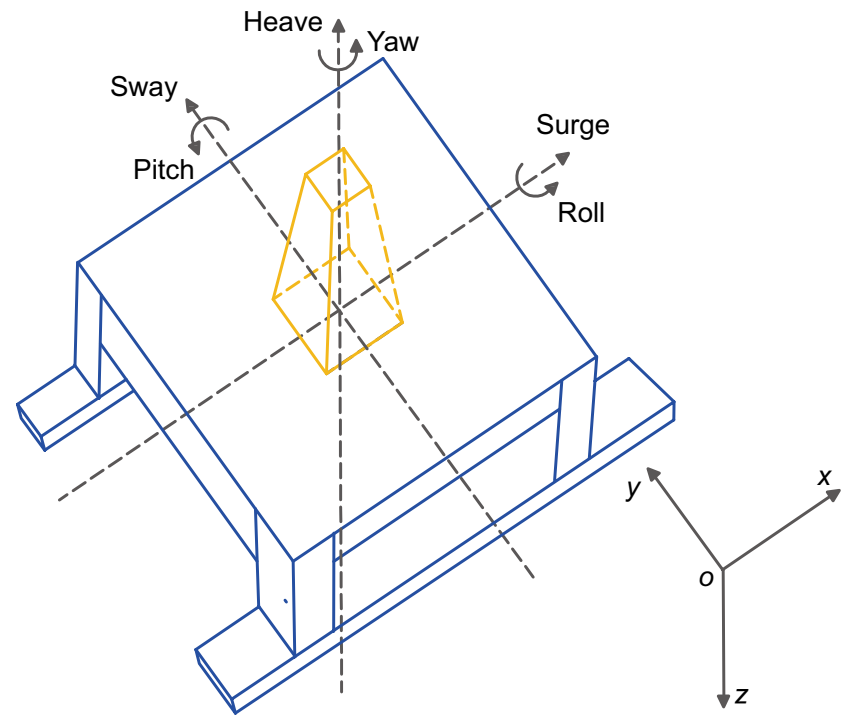

Fig. 3 Motions of platform

$P_{\mathrm{h}}=P_{\mathrm{h} 0}\left[\frac{V_{\mathrm{h} 0}}{V_{\mathrm{h} 0}+\left(A_{\mathrm{p}}-A_{\mathrm{r}}\right) Z_{\mathrm{t}}}\right]^{\gamma}$

$P_{\mathrm{L}}=P_{\mathrm{L} 0}\left(\frac{V_{\mathrm{L} 0}}{V_{\mathrm{L} 0}-A_{\mathrm{p}} Z_{\mathrm{t}}}\right)^{\gamma}$

Finally, substituting Eqs. (9) and (10) into Eq. (4), the tension force of the DAT applied on the riser system can be written as follows:

$F_{\mathrm{t}}=P_{\mathrm{h} 0} \frac{V_{\mathrm{h} 0}^{\gamma}\left(A_{\mathrm{p}}-A_{\mathrm{r}}\right)}{\left[V_{\mathrm{h} 0}+\left(A_{\mathrm{p}}-A_{\mathrm{r}}\right) Z_{\mathrm{t}}\right]^{\gamma}}-P_{\mathrm{L} 0} \frac{V_{\mathrm{L} 0}^{\gamma} A_{\mathrm{p}}}{\left(V_{\mathrm{L} 0}-A_{\mathrm{p}} Z_{\mathrm{t}}\right)^{\gamma}}-M g$

\subsection{Platform model}

A semi-submersible platform is selected for the multibody analysis due to its good performance of stability, great mobility and a wide range of applicable water depth (Zhu and Ou 2011). The motion of a drilling platform is the upper boundary of the multibody system and very important for the multibody mechanical analysis. The motion of a drilling platform is often characterized by six degree-of-freedom motions with surge, sway, heave, pitch, roll and yaw motions (Mao et al. 2010), as shown in Fig. 3.

The six degree-of-freedom motions of the platform are often determined based on the response amplitude operator (RAO). RAO defines the amplitude and phase relationship between the platform motion and wave frequency. Each degree-of-freedom motion of platform in the regular wave can be calculated as follows (Sexton and Agbezuge 1976; Chang et al. 2008): 
$S(t)=S_{0}+A_{0} R(w) \cos (w t+\varphi(w))$

where $S_{0}$ is the mean offset of the platform, $A_{0}$ is the amplitude of the regular wave, $R$ is the response amplitude, $w$ is the wave frequency and $\varphi$ is the phase difference between platform motion and wave.

\section{Simulation models}

A simulation model needs to be developed to conduct the multibody mechanical analysis based on established theoretical models of the riser system, tensioners and the platform. MATLAB/Simulink/Simscape is chosen for developing the multibody simulation model due to its good simulation environment for a three-dimensional (3D) multibody system. Users can model a multibody system using basic blocks representing bodies, joints and other blocks and integrate hydraulic, pneumatic and other physical systems into the established simulation model (Wang et al. 2016; Lapusan et al. 2016). Besides, users can also develop specific modules to meet simulation requirements, such as the marine environment load module. The multibody system is often split into several bodies during modeling. Each body of the multibody system will be built separately and then assembled together according to their topological relation, as shown in Fig. 4.

Figure 4 shows that the multibody system is split into five bodies. Body 1 is the LMRP and BOP, which is fixed on the seabed and connected to the riser system through a flex joint. Body 2 represents the riser system, which is a nonlinear structure. Body 3 shows the outer and inner pipe of the telescopic joint, which can slide relative to each other. The outer pipe of the telescopic joint connects to the riser system, while the inner pipe of the telescopic joint connects to the platform (Body 4) through a flex joint. Body 5 represents the DAT system, which is directly connected to the tensioner ring and provides a tension force for the riser system. Simulation models of Body 2 and Body 5 will be individually introduced in the following parts due to their complexity.

\subsection{Riser system}

The theoretical model of the riser system shown in Eqs. (1) and (2) can be solved based on the finite difference method, finite element method, rigid finite element method and lumped mass method (Adamiec-Wójcik et al. 2015). The lumped mass method is chosen for the riser analysis since there is a provided lumped mass method package of general use for flexible body modeling in Simscape. In the lumped mass method, the riser system is modeled using lumped masses connected by extensional and rotational springs

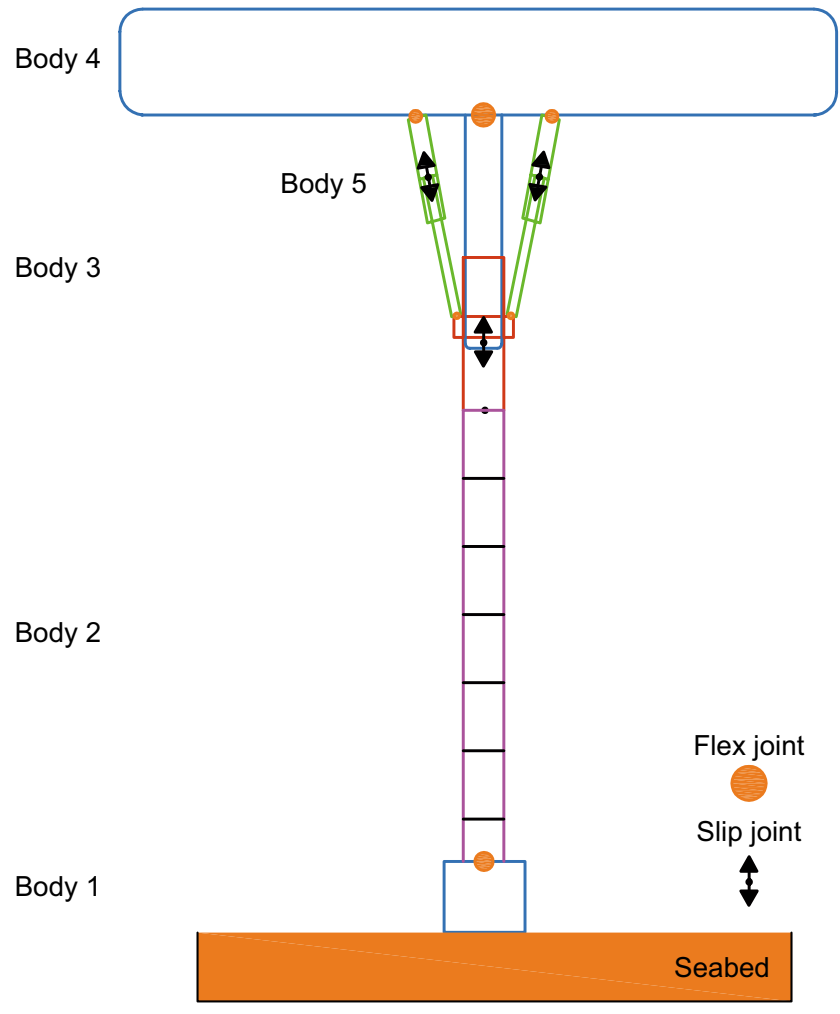

Fig. 4 Each part of the multibody system

including structural damping (Raman-Nair and Baddour 2003), as shown in Fig. 5.

Figure 5 shows that the riser system is divided into $n$ units. Each riser unit is formed by an elastic damping element and a rigid body element. The elastic damping element is used to define the translation spring coefficient $\left(k_{\mathrm{T}}\right)$, translation damping coefficient $\left(b_{\mathrm{T}}\right)$, rotational spring $\operatorname{coefficient}\left(k_{\mathrm{R}}\right)$ and rotational damping coefficient $\left(b_{\mathrm{R}}\right)$.

$k_{\mathrm{T}}=\frac{E A}{l}$

$b_{\mathrm{T}}=2 \zeta \sqrt{\mathrm{m} k_{\mathrm{T}}}$

$k_{\mathrm{R}}=\frac{E I}{l}$

$b_{\mathrm{R}}=2 \zeta \sqrt{J k_{R}}$

where $l$ is the unit length; $\zeta$ is the damping ratio, and its values range from 0 to $1 ; J$ is the moment of inertia of the riser unit about the axis of rotation.

The simulation model of a riser unit is established based on the lumped mass model in Simscape, as shown in Fig. 6. A solid block is used to define the structure parameters of a riser unit. The coordinate transformation module is set to 


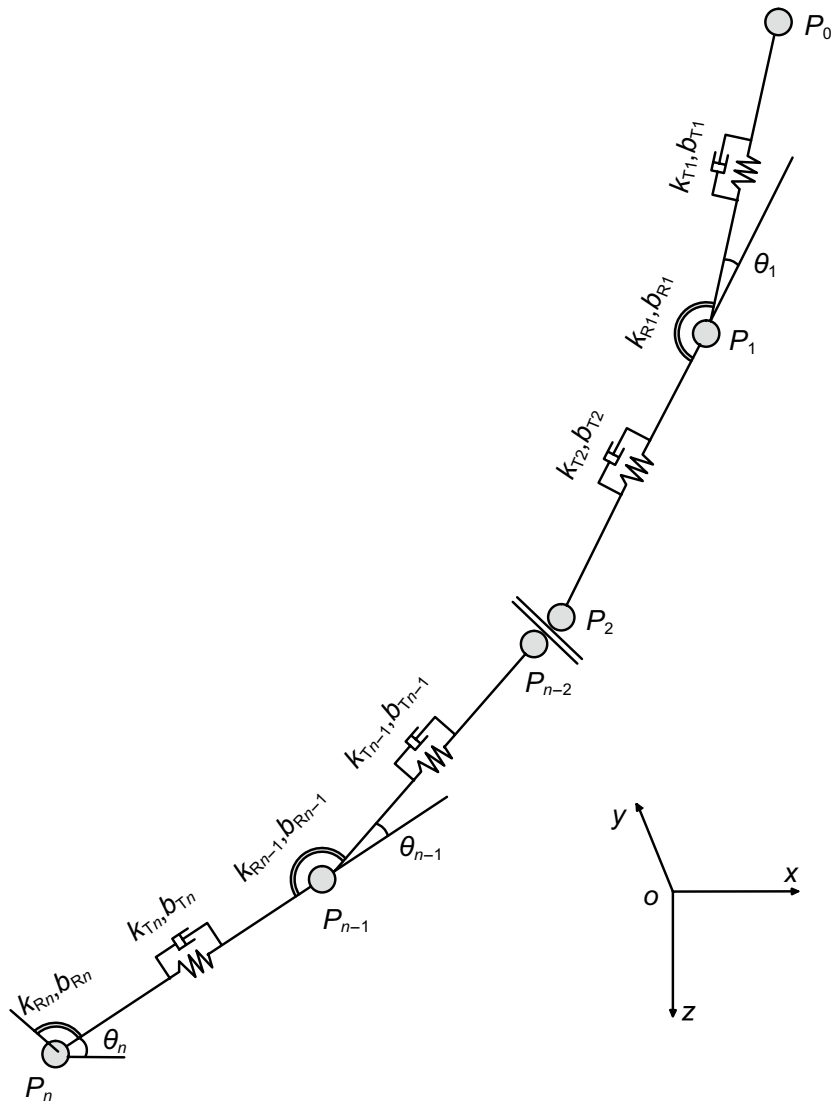

Fig. 5 The lumped mass model transfer the local coordinate system to a global coordinate system. The telescoping joint is used to define the spring stiffness and damping coefficient shown in Eqs. (13)-(16). A marine environment load module is developed based on MATLAB to calculate wave and current loads via the modified Morrison equation, as shown in Eq. (3). The water particle velocity induced by a wave, water particle acceleration induced by a wave and steady current velocity are calculated in the marine environment load module. Riser velocity and acceleration defined in Eq. (3) can be monitored and translated to the load calculate module for load calculation. A delay module, which can make time difference in data transmission, is set to avoid algebraic loop and improve calculation speed. The buoyancy module is set to apply the buoyancy force of the riser unit in sea water since the dry weight of the riser has been defined in the solid block.

\subsection{Tensioner system}

A tensioner is composed of a hydro-pneumatic tensioner cylinder, an oil-gas accumulator and several high-pressure and low-pressure gas vessels, as shown in Fig. 2. Each part of a tensioner can be simulated in Simscape fluids-hydraulics and multibody module, as shown in Fig. 7. A double-acting hydraulic cylinder is used to define the piston area, piston stroke and piston initial position. Gascharged hydraulic fluid accumulator 1 is set to simulate oil-gas accumulator and high-pressure gas vessels, while

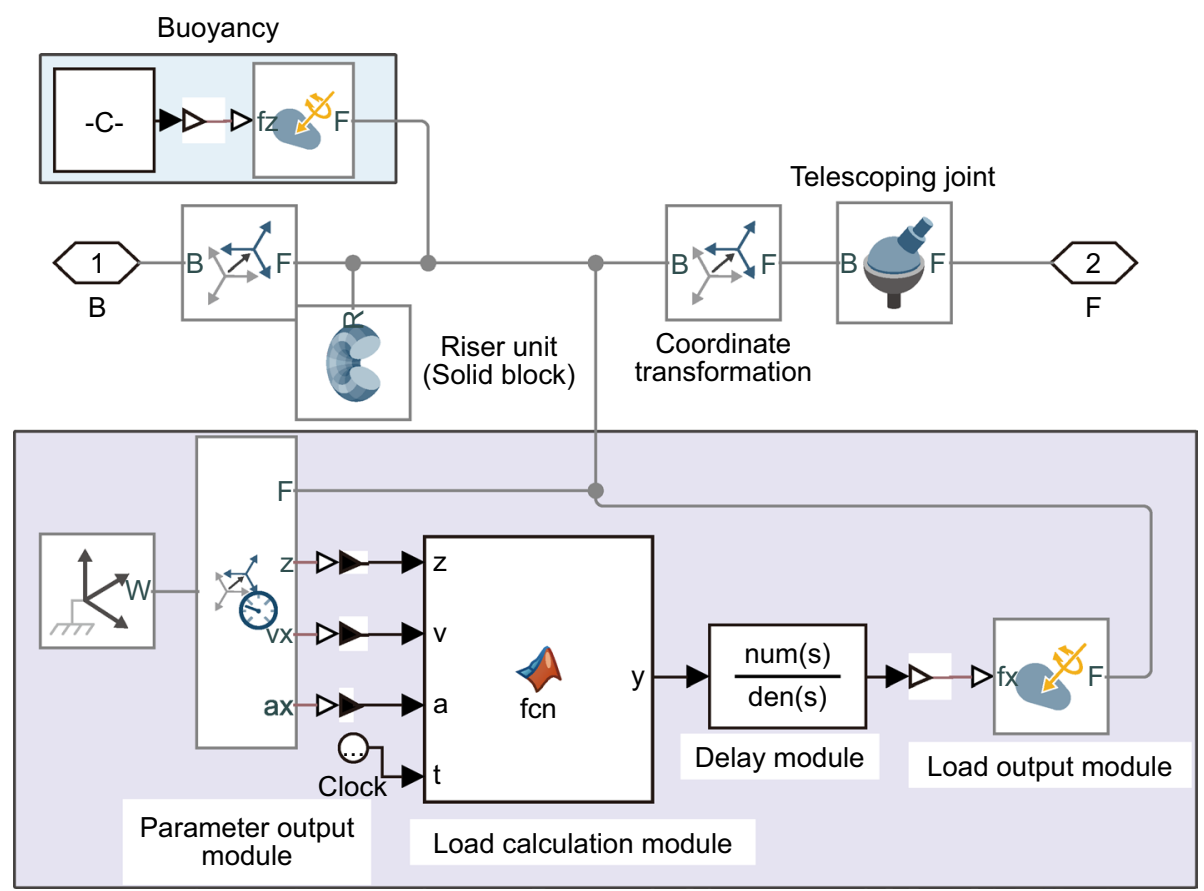

Marine environment load module

Fig. 6 Simulation model of a riser unit 


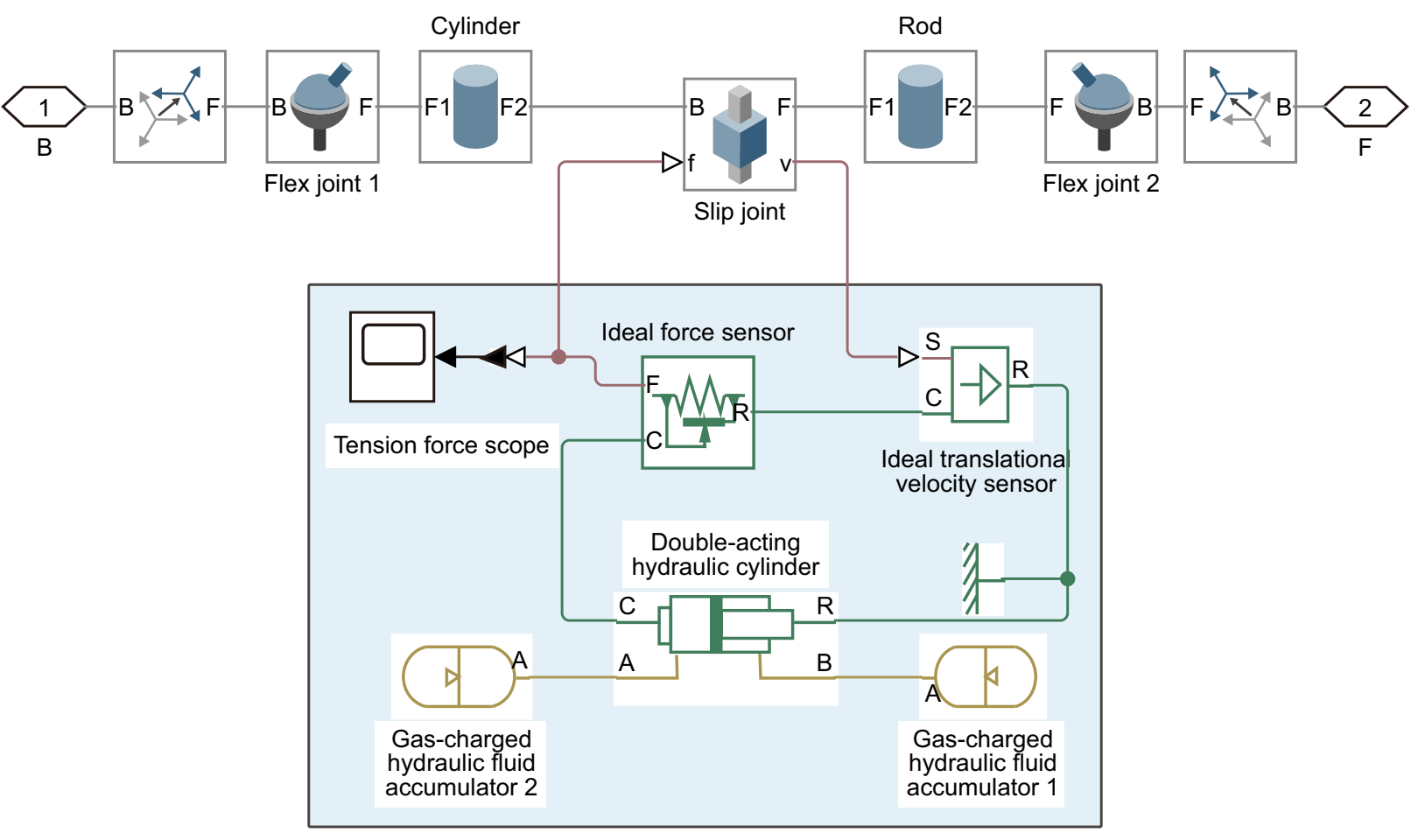

Hydro-pneumatic system

Fig. 7 Simulation model of a tensioner

gas-charged hydraulic fluid accumulator 2 is used to model low-pressure gas vessels. The ideal force sensor, ideal translational velocity sensor and tension force scope are set to monitor and display the key parameters of the tensioner during the simulation. Flex joints 1 and 2 are placed at the end of the piston and piston rod to connect the tensioner with the platform and riser tension ring, respectively.

\subsection{Multibody system}

Simulation models for complex riser (Body 2) and tensioner (Body 5) have been established. The other three bodies are simple and can be established directly in MATLAB. LMRP\&BOP (Body 1) and drilling platform (Body 4) are taken as rigid bodies, while the telescopic joint (Body 3 ) is simulated as two cylinders which can slide against each other. Then, a 3D multibody simulation model can be assembled through coordinates based on established simulation models of each body, as shown in Fig. 8. Each body in the multibody system is physically connected to one another by joints. The telescopic joint and tensioner assemblies are connected to the platform by flex joints. The lower part of the tensioners links to the riser tension ring with flex joints. A fixed joint is used to connect the lower part of the telescopic joint and the riser system. LMRP and BOP are connected to the riser system via a flex joint. Finally, a 3D multibody

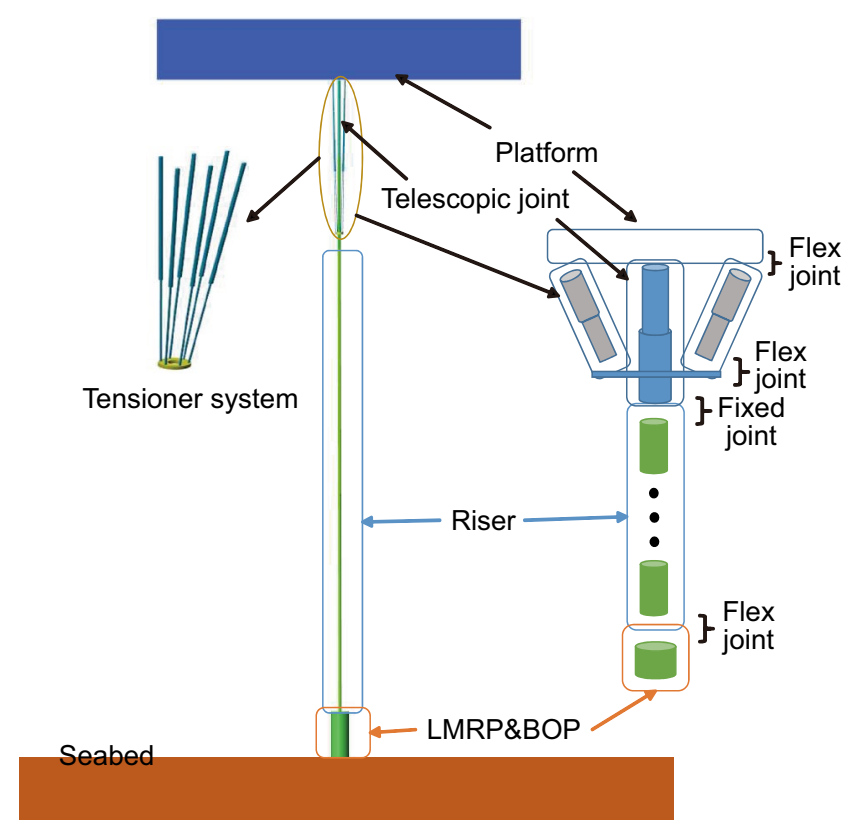

Fig. 8 3D Simulation model of the multibody system

simulation program with interactive graphics is developed and used for the following mechanical analysis of the deepwater drilling riser system. 
Table 1 Riser parameters

\begin{tabular}{ll}
\hline Parameters & Value \\
\hline Length of the riser system, m & 533 \\
Length of each riser joint, m & 15.24 \\
External diameter of risers, in & 21 \\
Wall thickness of risers, in & 1 \\
External diameter of buoyancy riser joints, m & 1.22 \\
Dry weight of each buoyancy riser joint, $\mathrm{kg}$ & 15,334 \\
Wet weight of each buoyancy riser joint, $\mathrm{kg}$ & 220 \\
Density of risers, $\mathrm{kg} / \mathrm{m}^{3}$ & 7850 \\
Elasticity modulus of risers, GPa & 206 \\
Density of seawater, $\mathrm{kg} / \mathrm{m}^{3}$ & 1025 \\
Rotation stiffness of UFJ, $\mathrm{kN} \mathrm{m} / \mathrm{deg}$ & 0 \\
Rotation stiffness of $\mathrm{LFJ}, \mathrm{kN} \mathrm{m} / \mathrm{deg}$ & 27
\end{tabular}

Table 2 DAT parameters

\begin{tabular}{lll}
\hline Components & Parameters & Value \\
\hline Hydraulic cylinder & Piston diameter, mm & 560 \\
& Piston rod diameter, mm & 230 \\
& Piston mass, kg & 6050 \\
& Stroke-length, m & \pm 7.5 \\
& Adiabatic gas constant & 1.4 \\
High-pressure gas vessels & Initial pressure, MPa & 2.08 \\
& Initial volume, m & 9.38 \\
Low-pressure gas vessels & Initial pressure, MPa & 0.15 \\
& Initial volume, $\mathrm{m}^{3}$ & 2.25 \\
\hline
\end{tabular}

\section{Results and discussion}

The proposed multibody simulation method is applied to an engineering case in the South China Sea. Basic parameters of the riser system and tensioners are listed in Tables 1 and 2, respectively. Current profiles with different surface current velocities in the South China Sea are shown in Fig. 9.

\subsection{Static characteristics}

The drilling riser system is often analyzed individually in previous studies (Chen et al. 2013). The developed multibody analysis program can also conduct riser analysis separately when tensioners are replaced by a constant force. The developed multibody analysis program is compared with ABAQUS which has been widely used for the riser analysis (Dai et al. 2009; Liu et al. 2016a, b; Liao et al. 2018) and the simulation program developed by Tian et al. (2020) to verify its correctness. The external diameter and

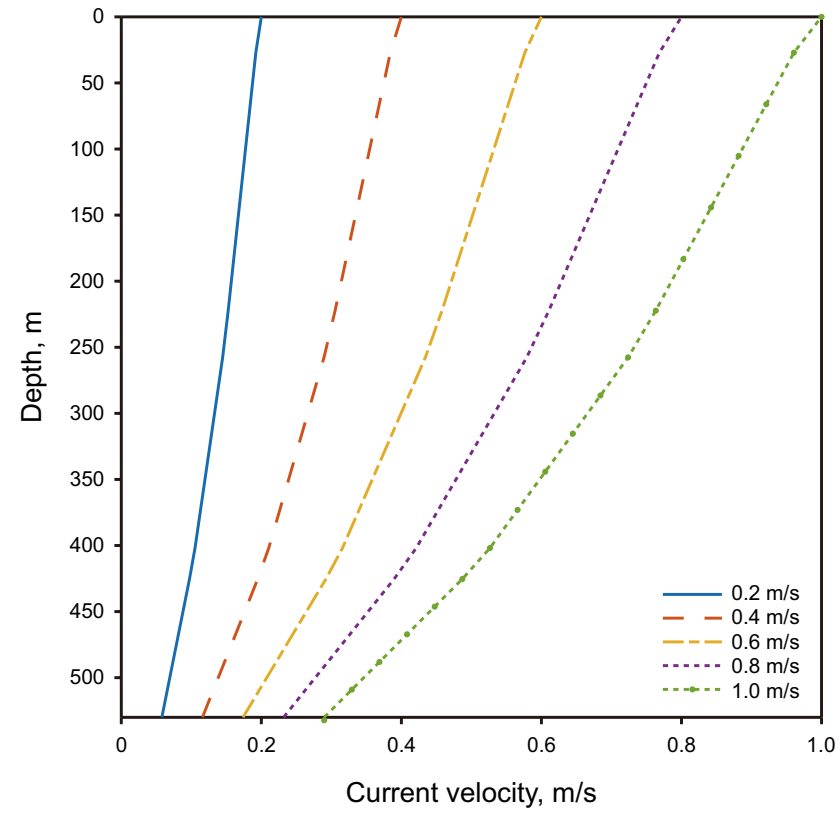

Fig. 9 Current profiles

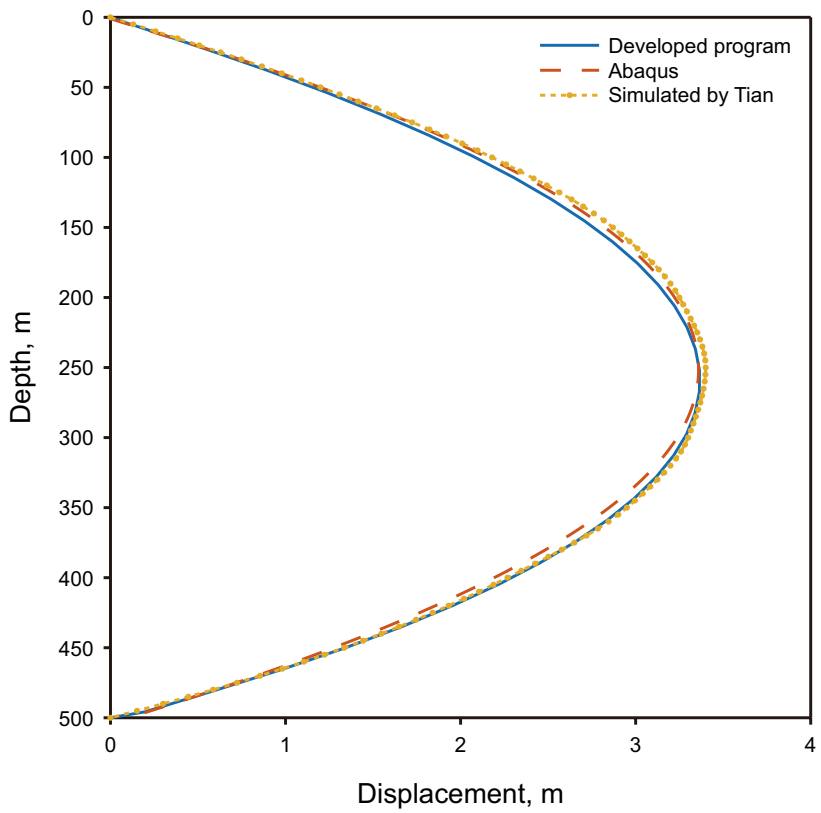

Fig. 10 Displacement of the riser system

wall thickness of risers are $0.324 \mathrm{~m}$ and $0.0165 \mathrm{~m}$, respectively. The top tension coefficient of the riser system is 1.5. The surface current velocity is $0.8 \mathrm{~m} / \mathrm{s}$, and the drag coefficient of the riser system is 1.2. Figure 10 shows the calculated lateral displacement based on the developed multibody analysis program, ABAQUS and the simulation 
program developed by Tian. The comparison results show that the lateral displacement of the riser system based on the three analysis programs is nearly the same. Then, the developed multibody analysis program is further used for multibody static analysis and compared with individual riser analysis.

The static characteristics of the multibody system in different current velocities are analyzed and compared with individual riser analysis results. The main difference between the two analysis models is that the DAT is simulated in the multibody analysis model, while it is assumed to be a constant tension force in the traditional individual riser analysis model. Figure 11 shows the displacement distribution of the riser system with DAT and with constant tension force 232t in different current velocities. It turns out that the lateral displacement of the riser system with DAT is smaller than that with constant tension force, which means the DAT can suppress the lateral deformation of the riser system. The bending moment of the riser system with DAT and with constant tension force is also extracted to study the influence of DAT on the riser deformation, as shown in Fig. 12. The results show that the bending moment of the riser system with DAT is different from that with constant tension force near sea surface. The main reason is that the DAT can induce a horizontal component force acting on the riser system when the riser system deforms in the lateral direction. The horizontal component forces are $337 \mathrm{~N}$, $3166 \mathrm{~N}$ and $8765 \mathrm{~N}$ in current velocities $0.2 \mathrm{~m} / \mathrm{s}, 0.6 \mathrm{~m} / \mathrm{s}$ and $1.0 \mathrm{~m} / \mathrm{s}$, respectively. The induced horizontal component

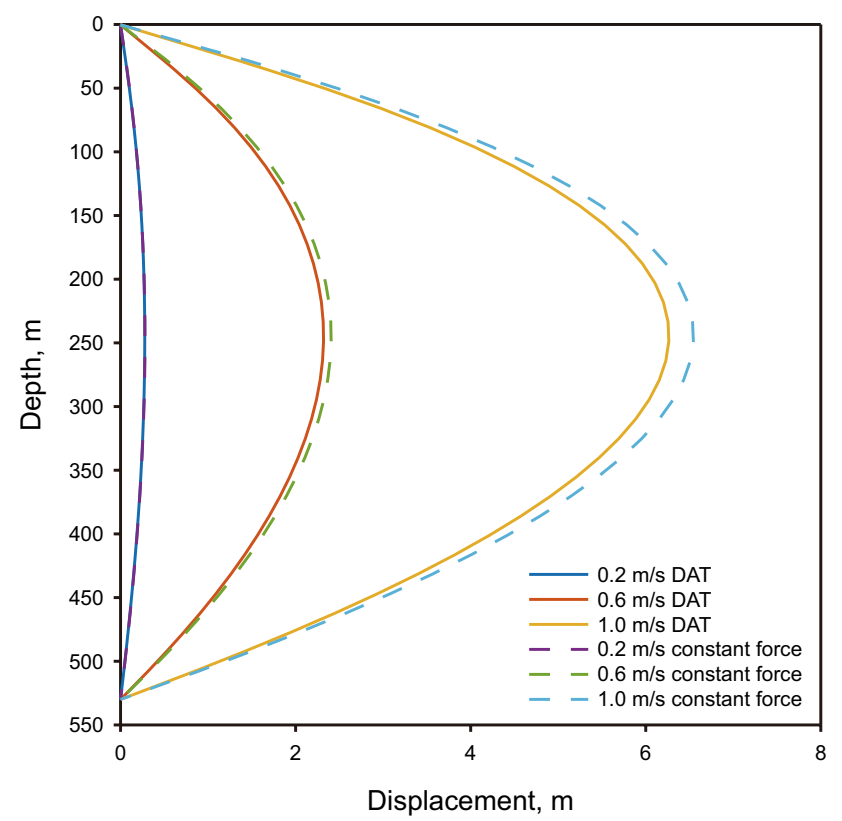

Fig. 11 Displacement of the riser system in different current velocities

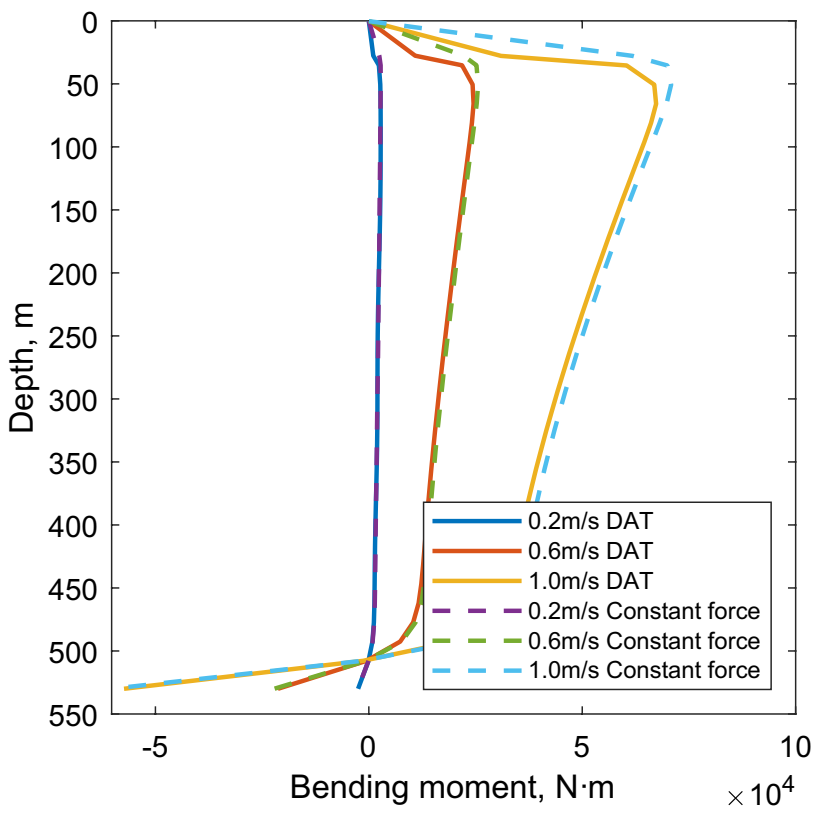

Fig. 12 Bending moment of the riser system in different current velocities

force which is opposite to the current load can reduce the bending moment and deformation of the riser system.

\subsection{Dynamic characteristics}

The riser system vibrates under various dynamic loads, especially motions of the drilling platform. The developed multibody analysis program can conduct a dynamic analysis of the multibody system under six degree-of-freedom motions of platform, as shown in Fig. 3. The yaw motion of the drilling platform has no influence on the riser system since a swivel bearing is installed on the telescopic joint to compensate the yaw motion. In order to evaluate the influence of platform motions on riser dynamics, riser dynamics under the other five degree-of-freedom motions of the platform is analyzed separately. The current velocity is assumed to be zero. However, the hydrodynamic loads on the riser system due to the riser vibration is calculated based on the developed load calculation module shown in Fig. 6.

\subsubsection{Heave motion of platform}

The top tension force of the riser system is often assumed to be constant in previous studies (Chang and Chen 2010; Wang et al. 2010). However, the heave motion in which the platform moves up and down due to wave may cause axial force vibration of the riser system although tensioners are equipped to compensate the heave motion of the platform. The heave motion amplitude and period are assumed to be $2 \mathrm{~m}$ and $15 \mathrm{~s}$, respectively. The axial force of the riser system 


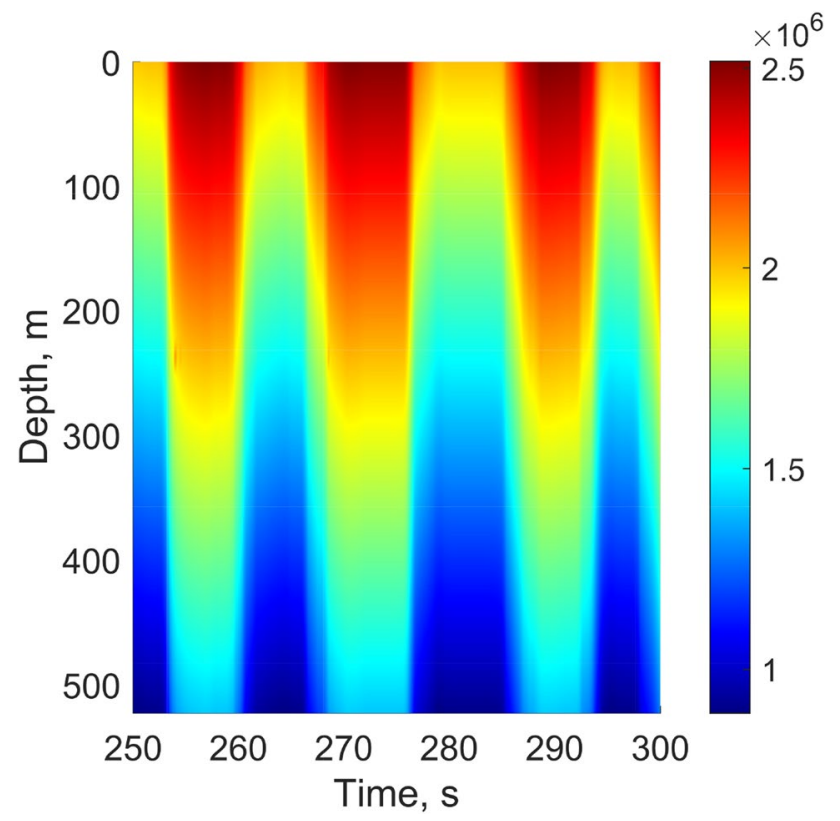

Fig. 13 Axial force of the riser system

is analyzed based on the developed multibody analysis program. Figure 13 shows the axial force of the riser system under the heave motion of the platform. It turns out that the axial force of the riser system varies periodically with platform heave motion. In order to evaluate the variation amplitude and phase of the axial force along the riser system, the exact axial riser force in four specified depths is extracted,

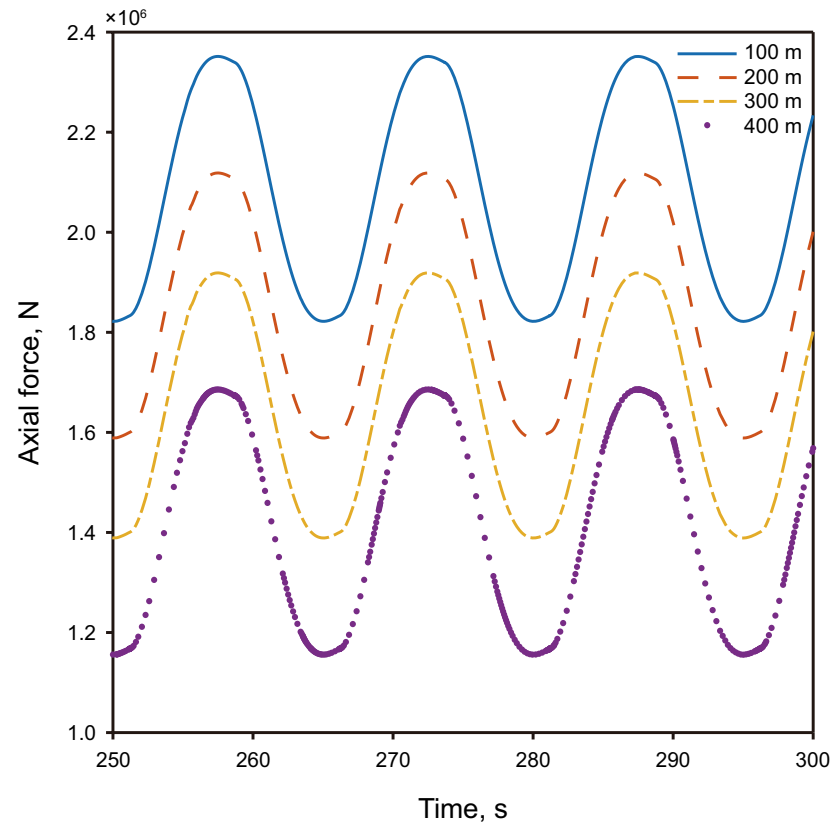

Fig. 14 Axial force of the riser system in specified depths as shown in Fig. 14. It shows that the variation amplitude and phase of the axial force are basically the same along the riser system. Besides, the influence of the heave motion period and amplitude on the amplitude of axial force is also analyzed, as shown in Fig. 15. The amplitude of platform motion has an obvious influence on the axial force amplitude of the riser system, while the influence of the period is little. The axial force amplitude of the riser system due to the heave motion of the platform is non-negligible while it is often neglected in traditional analysis.

\subsubsection{Surge and sway motions of platform}

The drilling platform moves back and forth in horizontal direction under both surge and sway motions. Therefore, the influence of surge and sway motions on riser dynamics is the same and will be analyzed together. Traditionally, the surge or sway motion is directly applied on the top end of the riser system in an individual riser analysis model in which DAT is not considered. Riser dynamics under surge or sway motion of the platform is analyzed based on a developed multibody analysis program and compared with that in the individual riser analysis model. The surge or sway motion amplitude and period are assumed to be $2 \mathrm{~m}$ and $15 \mathrm{~s}$, respectively. Figures 16 and 17 show that the surge or sway motion transmits from the top to the bottom of the riser system. The lateral displacement of the riser system in the multibody system seems to be the same with that in the individual riser analysis model. In order to compare the displacement of the riser system exactly, the displacement of the riser system in four

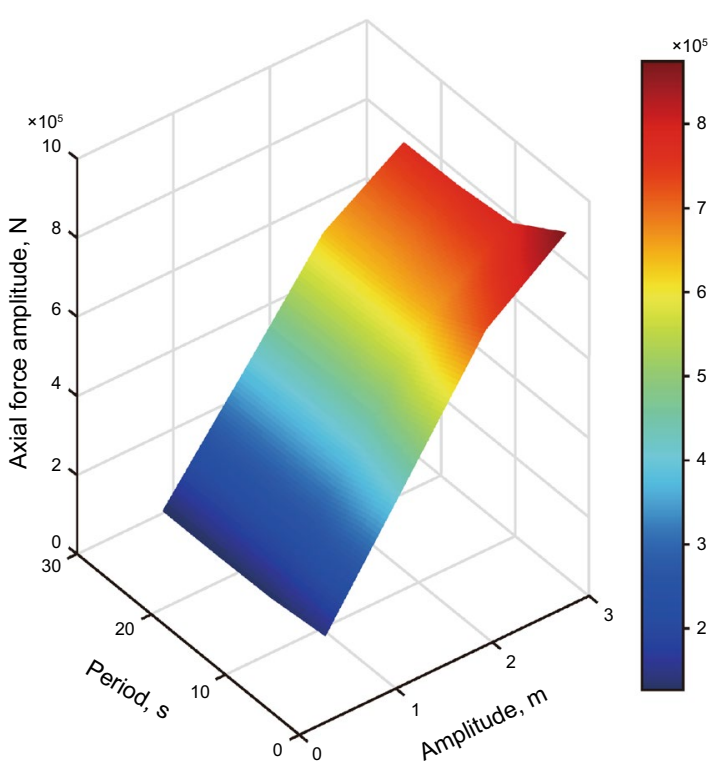

Fig. 15 Axial force amplitude under different heave motion amplitudes and periods 


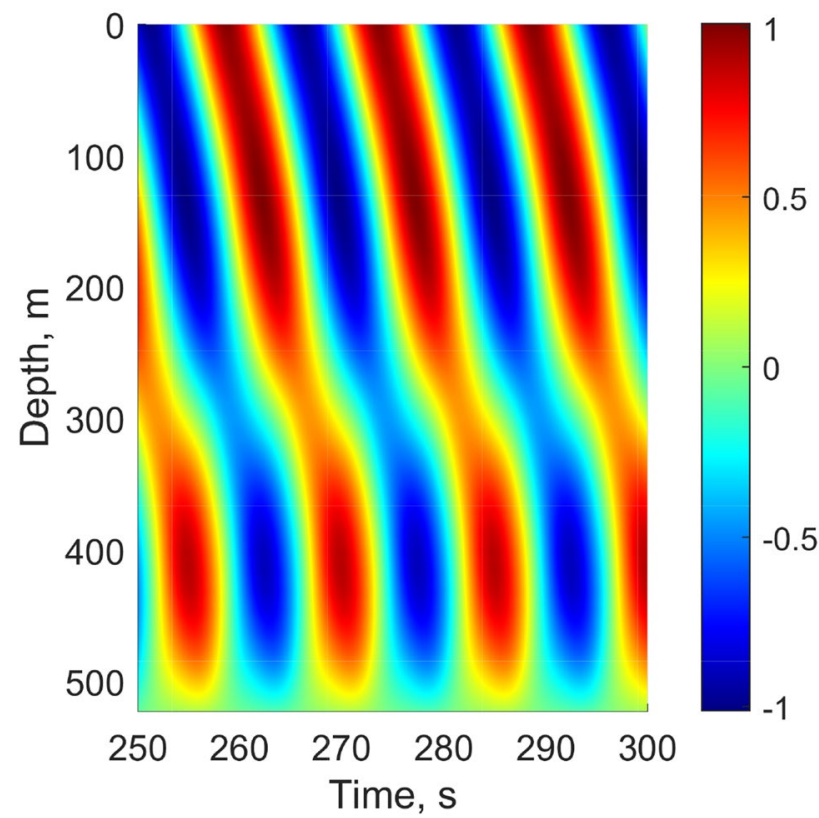

Fig. 16 Lateral displacement of the riser system without DAT

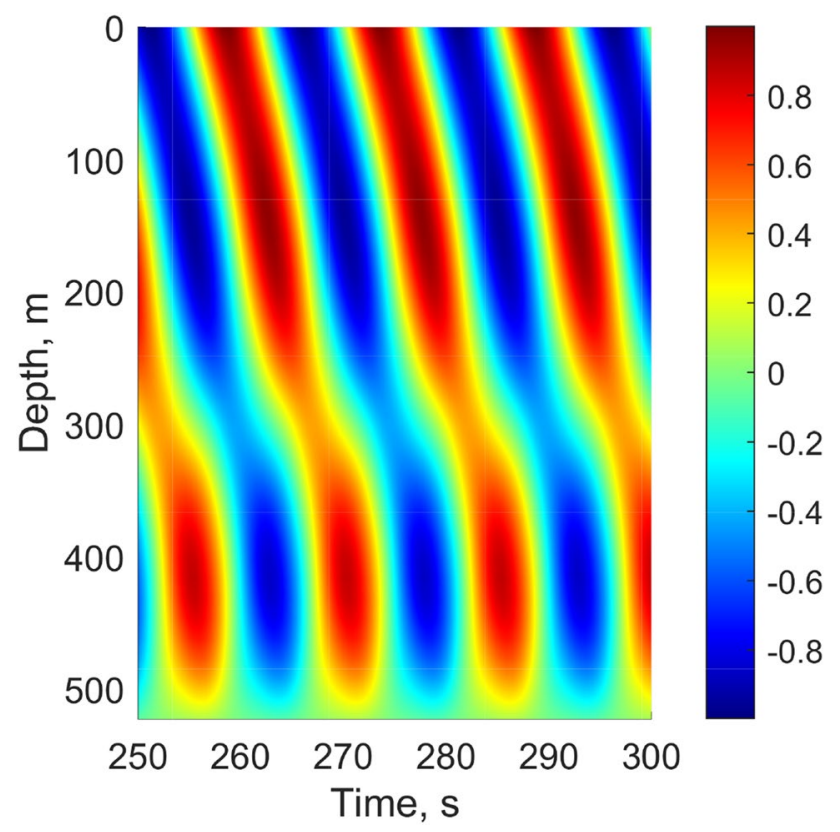

Fig. 17 Lateral displacement of the riser system with DAT

specified depths including $100 \mathrm{~m}, 200 \mathrm{~m}, 300 \mathrm{~m}$ and $400 \mathrm{~m}$ is shown in Fig. 18. It turns out that the displacement of the riser system with DAT is smaller than that without DAT, which is in accordance with static analysis results. The main reason is that the DAT can suppress the lateral deformation of the riser system as explained in static analysis. Besides,

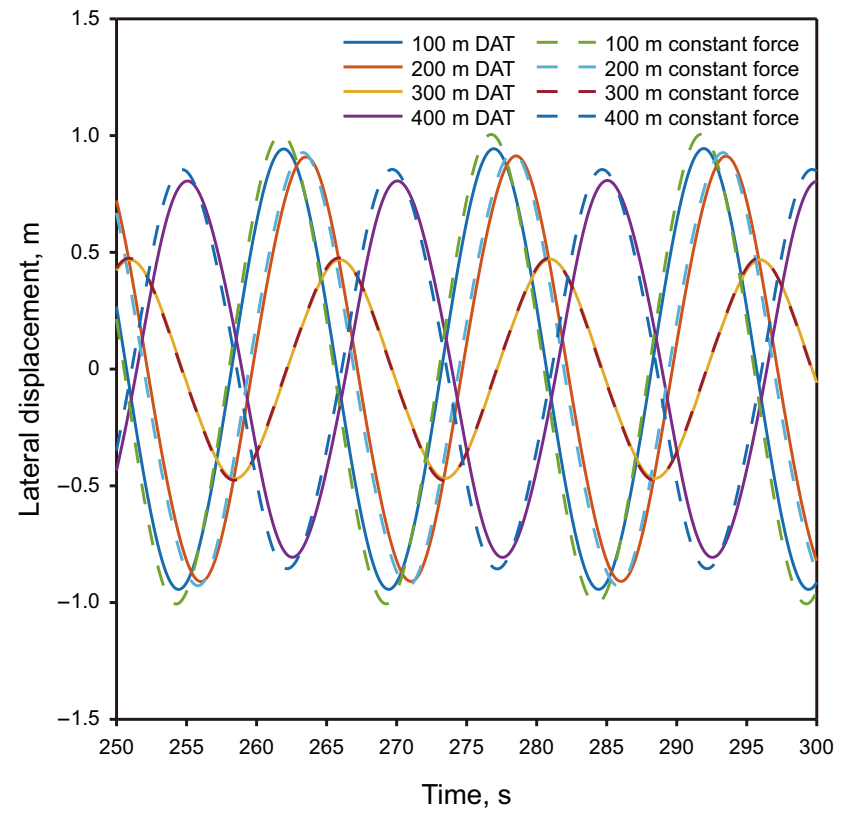

Fig. 18 Lateral displacement of the riser system in specified depths

it also seems that there is a vibration phase lag of the riser system with DAT compared with that without DAT due to the flexibility of DAT.

\subsubsection{Roll and pitch motions of platform}

Roll and pitch are rotational movements of the drilling platform. The roll and pitch seem to have little influence on riser dynamics since the riser system connects to the platform via an upper flex joint with no or little rotational stiffness. However, the roll and pitch motions may transfer to the riser system through tensioners in the multibody system. The roll or pitch motion amplitude and period are assumed to be $4^{\circ}$ and $10 \mathrm{~s}$, respectively. Figure 19 shows the bending moment of the riser system under the roll or pitch motion. The roll or pitch motion causes the riser system to vibrate laterally, and the vibration transfers from the top to the bottom of the riser system. The maximum bending moment of the riser system in this condition is $32.8 \mathrm{kN} \mathrm{m}$, which can induce the bending stress with $13.354 \mathrm{MPa}$. Besides, the maximum bending moment of the riser system in different roll amplitudes and periods is also analyzed, as shown in Fig. 20. The bending moment of the riser system increases with roll amplitude while decreases with the roll period.

\subsubsection{Combined motions of platform}

A semi-submersible drilling platform in the South China Sea is selected for the multibody analysis to contrastively evaluate the influence of each type of platform motion 


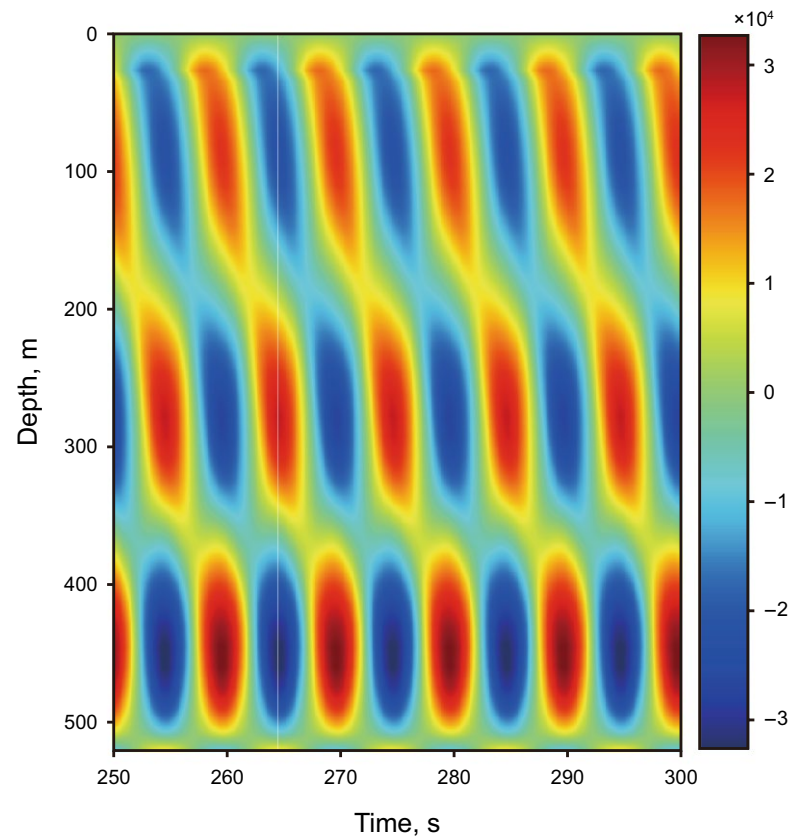

Fig. 19 Bending moment of the riser system due to roll

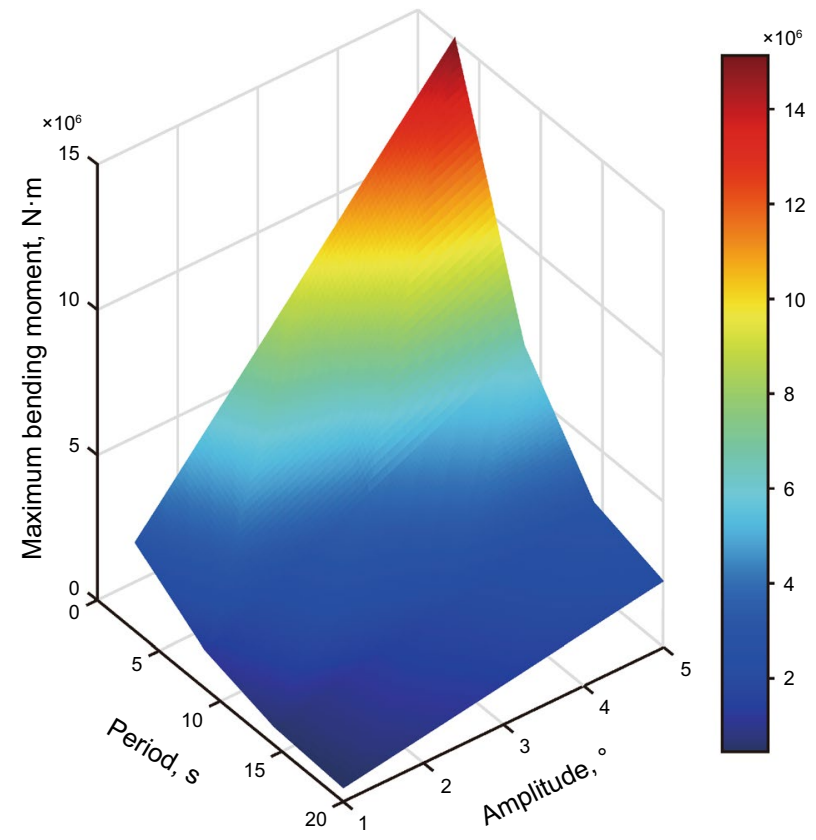

Fig. 20 Maximum bending moment of the riser system under different roll amplitudes and periods

on riser dynamics. Assuming the $x$-axis of the platform shown in Fig. 3 is also the wave propagation direction, platform motions are composed of heave, surge and pitch in this condition. RAOs of the heave, surge and pitch of

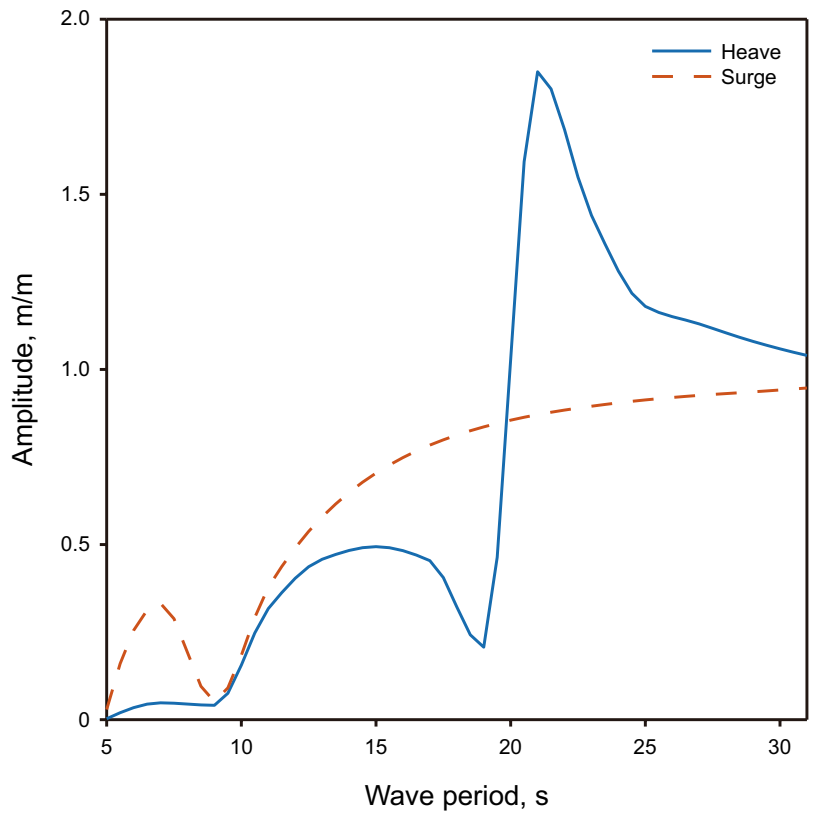

Fig. 21 RAO of heave and surge motion

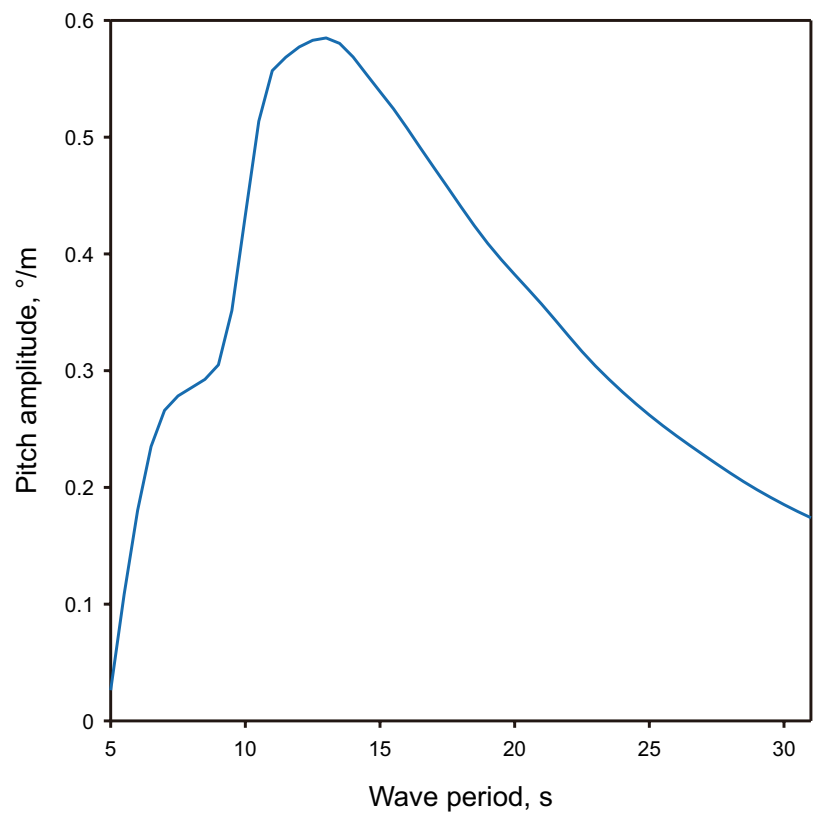

Fig. 22 RAO of pitch motion

the selected platform are shown in Figs. 21 and 22. The wave height is $3 \mathrm{~m}$, and the wave period ranges from 5 to $30 \mathrm{~s}$. Motions of the platform due to waves are calculated based on Eq. (12) and then applied in the multibody system model. The maximum stress amplitude of the riser system due to each platform motion is shown in Fig. 23. 


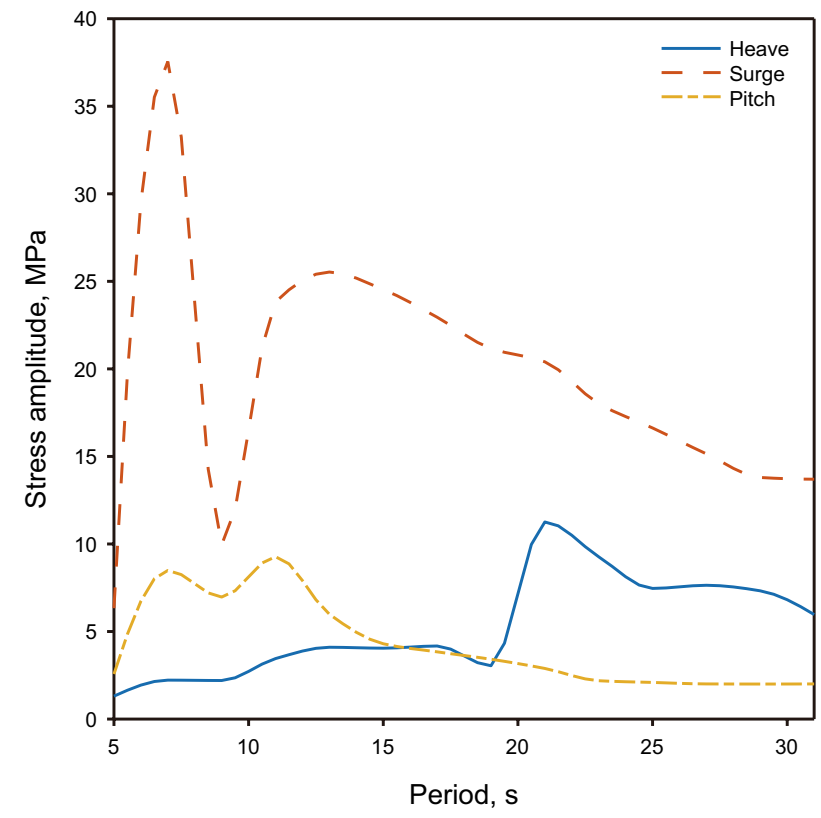

Fig. 23 Stress amplitude under different platform motions

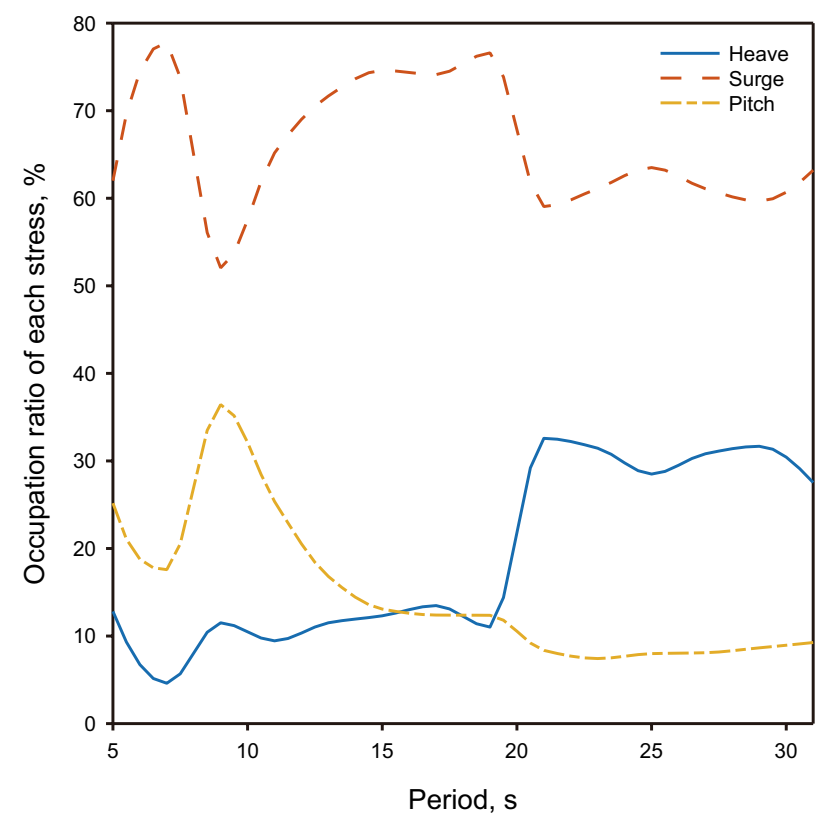

Fig. 24 Occupation ratio of each stress under different platform motions

The occupation ratio of each stress is extracted to show the importance of each platform motion directly, as shown in Fig. 24. It turns out that the surge motion has the largest influence on the stress amplitude of the riser system. The stress amplitude of the riser system due to heave and pitch motions is relatively small but cannot be neglected.

\section{Conclusions}

In this paper, a challenging problem has been addressed: mechanical analysis of deepwater drilling riser system based on multibody system dynamics. The theory models of a multibody system including a riser system, a drilling platform and DAT are established. A simulation method for the deepwater drilling riser system/tensioners/platform system is proposed. The drilling riser system is modeled as a massspring-damping system, tensioners are modeled as a fluidshydraulics system, and the platform is taken as a rigid body with six degree-of-freedom motions. Finally, the multibody simulation model is assembled in MATLAB according to their topological relation. A 3D multibody simulation program with interactive graphics is developed.

The developed multibody simulation program is used to conduct riser static analysis and compared with the riser individual analysis model. The static analysis results of the riser system without DAT based on the developed multibody simulation program and ABAQUS are nearly the same, which verifies the correctness of the developed multibody simulation program. The developed multibody simulation program is further used for multibody static analysis and compared with individual riser analysis. It turns out that the lateral displacement and bending moment of the riser system with DAT are smaller than that with constant tension force in riser individual analysis model, which means the DAT can suppress the lateral deformation of the riser system.

The developed multibody simulation program is then applied in riser dynamic analysis under various platform motions. Under surge and sway motions of the platform, the dynamic displacement of the riser system with tensioners is also smaller than that without tensioners due to the tensioner suppression effect. Besides, heave, roll and pitch motions of the platform also affect the dynamic characteristics of the riser system through tensioners. The heave motion of the platform induces a uniform axial vibration of the riser system, while roll and pitch motions of the platform excite the riser system to vibrate laterally. The stress amplitude of the riser system due to heave, roll and pitch motions is relatively small but cannot be neglected.

Acknowledgements This work was financially supported by National Natural Science Foundation of China (Grant No. 51809279), Major National Science and Technology Program (Grant No. 2016ZX05028001-05), National Key R\&D Program of China (Grant No. 2017YFC0804500), Program for Changiiang Scholars and Innovative Research Team in University (Grant No. IRT14R58), the Fundamental Research Funds for the Central Universities (Grant No. 20CX02302A) and the Opening Fund of National Engineering Laboratory of Offshore Geophysical and Exploration Equipment (Grant No. 20CX02302A).

Open Access This article is licensed under a Creative Commons Attribution 4.0 International License, which permits use, sharing, adaptation, distribution and reproduction in any medium or format, as long 
as you give appropriate credit to the original author(s) and the source, provide a link to the Creative Commons licence, and indicate if changes were made. The images or other third party material in this article are included in the article's Creative Commons licence, unless indicated otherwise in a credit line to the material. If material is not included in the article's Creative Commons licence and your intended use is not permitted by statutory regulation or exceeds the permitted use, you will need to obtain permission directly from the copyright holder. To view a copy of this licence, visit http://creativecommons.org/licenses/by/4.0/.

\section{References}

Adamiec-Wójcik I, Brzozowska L, Drąg Ł. An analysis of dynamics of risers during vessel motion by means of the rigid finite element method. Ocean Eng. 2015;106:102-14. https://doi. org/10.1016/j.oceaneng.2015.06.053.

Amirouche F. Fundamental of multibody dynamics. New York: Springer; 2006. https://doi.org/10.1007/b137682.

Bauchau OA. Flexible multibody dynamics. New York: Springer; 2011. https://doi.org/10.1007/978-94-007-0335-3.

Cha JH, Roh M, Lee KY. Dynamic response simulation of a heavy cargo suspended by a floating crane based on multibody system dynamics. Ocean Eng. 2010;37:1273-91. https://doi. org/10.1016/j.oceaneng.2010.06.008.

Chang YJ, Chen GM, Sun YY, et al. Nonlinear dynamic analysis of deepwater drilling risers subjected to random loads. China Ocean Eng. 2008;22(4):683-91.

Chang YJ, Chen GM. Theoretical investigation and numerical simulation of dynamic analysis for ultra-deepwater drilling risers. J Ship Mech. 2010;14(6):596-605. https://doi.org/10.3969/j. issn.1007-7294.2010.06.004.

Chen BQ, Yu J, Yu Y, et al. Study on key performance parameters of hydro-pneumatic tensioner for top tensioned riser. Appl Ocean Res. 2019;84:206-15. https://doi.org/10.1016/j. apor.2019.01.004.

Chen GM, Liu XQ, Chang YJ, et al. Advances in technology of deepwater drilling riser and wellhead. J China Univ Pet. 2013;37(5):129-39. https://doi.org/10.3969/j.issn.16735005.2013.05.019 (in Chinese).

Dai W, Gao F, Bai Y. FEM analysis of deepwater drilling risers under the operability and hang-off working conditions. J Mar Sci Appl. 2009;8(2):156-62. https://doi.org/10.1007/s1180 4-009-8114-0

Ham SH, Roh M, Lee H, et al. Multibody dynamic analysis of a heavy load suspended by a floating crane with constraintbased wire rope. Ocean Eng. 2015;109:145-50. https://doi. org/10.1016/j.oceaneng.2010.06.008.

Haziri S. Development of simulation model for virtual testing and design of a riser tensioner system. Master thesis, University of Agder, Norway; 2011.

$\mathrm{Ku}$ N, Ha S. Dynamic response analysis of heavy load lifting operation in shipyard using multi-cranes. Ocean Eng. 2014;83:63-75. https://doi.org/10.1016/j.oceaneng.2014.03.026.

Lang DW, Real J, Lane M. Recent developments in drilling riser disconnect and recoil analysis for deepwater applications. In: The 28th international conference on ocean, offshore and arctic engineering, Hawaii, USA; 2009. https://doi.org/10.1115/ OMAE2009-79427

Lapusan C, Balan R, Hancu O, et al. Development of a multi-room building thermodynamic model using Simscape library. Energy
Procedia. 2016;85:320-8. https://doi.org/10.1016/j.egypr o.2015.12.258

Lee HW, Roh M. Review of the multibody dynamics in the applications of ships and offshore structures. Ocean Eng. 2018;167:6576. https://doi.org/10.1016/j.oceaneng.2018.08.022.

Lee H, Roh M, Ham SH, et al. Dynamic simulation of the wireline riser tensioner system for a mobile offshore drilling unit based on multibody system dynamics. Ocean Eng. 2015;106:485-95. https://doi.org/10.1016/j.oceaneng.2015.07.028.

Liao ML, Zhou YC, Su YN, et al. Dynamic analysis and multiobjective optimization of an offshore drilling tube system with pipe-in-pipe structure. Appl Ocean Res. 2018;75:85-99. https ://doi.org/10.1016/j.apor.2018.03.010.

Liu K, Chen GM, Chang YJ, et al. Nonlinear dynamic analysis and fatigue damage assessment for a deepwater test string subjected to random loads. Pet Sci. 2016a;13:126-34. https://doi. org/10.1007/s12182-015-0063-4.

Liu XQ, Chen GM, Chang YJ, et al. Drift-off warning limits for deepwater drilling platform/riser coupling system. Pet Explor Dev. 2016b;43(4):641-6. https://doi.org/10.1016/S1876 -3804(16)30082-9.

Mao DF, Duan ML, Wang Y, et al. Model test investigation on an innovative lifting system for deepwater riser installation. Pet Sci. 2010;7:547-54. https://doi.org/10.1007/s1218 2-010-0107-8.

Park HI, Jung DH. A finite element method for dynamic analysis of long slender marine structures under combined parametric and forcing excitations. Ocean Eng. 2002;29:1313-5. https://doi. org/10.1016/s0029-8018(01)00084-1.

Patel MH, Seyed FB. Review of flexible riser modelling and analysis techniques. Eng Struct. 1995;17(4):293-304. https://doi. org/10.1016/0141-0296(95)00027-5.

Raman-Nair W, Baddour RE. Three-dimensional dynamics of a flexible marine riser undergoing large elastic deformations. Multibody Syst Dyn. 2003;10:393-423. https://doi. org/10.1023/a:1026213630987.

Sexton RM, Agbezuge LK. Random wave and vessel motion effects on drilling riser dynamics. In: Offshore Technology Conference, Dallas, Texas, USA; 1976. http://doi.org/10.4043/2650-MS.

Sullivan EO, Brekke JN, Dib M. Riser deployment and hang-off analysis for a harsh environment deepwater site. In: Proceedings of the 23rd International Conference on Offshore Mechanics and Arctic Engineering, Vancouver, British Columbia, Canada; 2004. https://doi.org/10.1115/omae2004-51632.

Tian DQ, Fan HH, Leira BJ, et al. Study on the static behavior of installing a deep-water drilling riser on a production platform. J Pet Sci Eng. 2020;185:106652. https://doi.org/10.1016/j.petro 1.2019.106652.

Wang T, Liu YJ. Dynamic response of platform-riser coupling system with hydro-pneumatic tensioner. Ocean Eng. 2018;166:172-81. https://doi.org/10.1016/j.oceaneng.2018.08.004.

Wang KP, Xue HX, Tang WY. Numerical simulation of hydropneumatic tensioner for coupled deepwater platform system. J Shanghai Jiao Tong Univ. 2013;46(10):1652-7. https://doi. org/10.1007/s11783-011-0280-z (in Chinese).

Wang L, Sweetman B. Multibody dynamics of floating wind turbines with large-amplitude motion. Appl Ocean Res. 2013;43:1-10. https://doi.org/10.1016/j.apor.2013.06.004.

Wang XF, Li X, Wang JH, et al. Data-driven model-free adaptive sliding mode control for the multi degree-of-freedom 
robotic exoskeleton. Inf Sci. 2016;327:246-57. https://doi. org/10.1016/j.ins.2015.08.025.

Wang T, Zhang XZ, Zhu WQ. Vessel motion effects on nonlinear dynamics of deepwater drilling riser. J Ship Mech. 2010;14(6):606-18. https://doi.org/10.3969/j. issn.1007-7294.2010.06.005.

Yang C, Du JB, Cheng ZB, et al. Offshore platform-marine-riserunderwater-wellhead coupling system analysis and optimization in multibody dynamics. In: Chinese Society of Mechanics academic conference, Beijing, China. 2017 (in Chinese).

Zhang L, Chang YJ, Liu XQ, et al. AMESim-based modeling and simulation of platform riser tensioner. China Pet Mach.
2013;41(12):38-42. https://doi.org/10.3969/j.issn.10014578.2013.12.010 (in Chinese).

Zhang SY, Liu XQ, Chang YJ, et al. Dynamic characteristic analysis on deepwater drilling platform/tensioner/riser coupling system. J China Univ Pet. 2019;43(2):123-30. https://doi.org/10.3969/j. issn.1673-5005.2019.02.015 (in Chinese).

Zhou JL, Xu LB. Research progress of key technologies for deep water drilling risers. China Offshore Oil Gas. 2018;30(4):135-43. https ://doi.org/10.11935/j.issn.1673-1506.2018.04.016 (in Chinese).

Zhu H, Ou JP. Dynamic performance of a semi-submersible platform subject to wind and waves. J Ocean Univ China. 2011;10(2):12734. https://doi.org/10.1007/s11802-011-1755-z. 